\title{
THE LAST WORD
}

\section{PUBLIC UNDERSTANDING AS A KEY TO COMMERCIAL SUCCESS}

\author{
by Amanda Iles
}

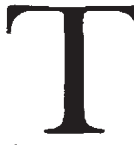

lo most people, public relations means promotion of companies-and their products and services. But for the young biotechnology industry, public relations must promote something more: Public understanding. Demystifying applied biological science can play a crucial role in the commercial success of individual biotech companies. Beyond that, the skill with which companies communicate will directly affect the acceptance and growth of the entire industry.

Whether the eyes of the world (and the media) gaze on the biotech industry with fondness or apprehension, they gaze steadily and with great curiosity. That is why today small biotechnology companies can often influence public opinion as much as larger firms: They can further their own cause and steadily advance the public's grasp of biotechnology-goals that are inextricably linked.

It is essential to seize the communications initiative early, to answer questions even before they are asked. Companies can and should begin communicating with the public long before they need to promote products or stock. They can do much to build acceptance of their endeavors, dispel fear of the unknown, and lay the groundwork for future markets for their products. Even small companies can take simple steps, at a pace modest enough to match their budgets, to effectively communicate with the outside world.

By beginning early, small companies can gain certain advantages. Most biotech companies don't know it, but they will never again have a better opportunity to communicate. When a company doesn't have anything to sell, it can speak in relaxed terms and take time to educate. Beginning early also allows time to practice. There is a chance to develop the skills and the spokespersons a company will need later to discuss products, public stock offerings - or unforseen events. And if a company can communicate the basics better than its competition, the public may remember that.

Trade organizations such as the Industrial Biotechnology Association (IBA) promote broad-based issues and educate the public in general ways. But trade organizations will always rely on member companies to deliver much of the news to the media. Only those who are closest to a technology are in a position to open their doors to the public and explain their work on a down-to-earth level.

One of the arts of public communication is to say enough, but not too much. Even though it is often necessary to keep quiet about proprietary research, excessive silence can heighten both expectations and fears. Competitors may be kept guessing, but so will the average citizen. The challenge is to find a middle ground. A company developing recombinant insulin can discuss its work without getting too specific about control sequences or restriction enzymes. It can discuss the lack of a human supply, explaining that some people become allergic to animal insulin. The majority of the public will not care about the scientific details, and the competition need never know them.

Some innovative biotech products may encounter considerable prejudice in the marketplace. Wise industry players will anticipate these situations and begin educating their future customers early. This is the approach used by International Biochemicals Group (IBG, London, U.K.), a small British company selling strains of microbes that clean up sewage. Sanitary engineers have traditionally used a mechanical and hydraulic approach; IBG has helped them understand the role microbes play in waste breakdown. And Syntro Corp. (San Diego, CA), which will eventually introduce a set of animal vaccines based on recombinant technology, has already begun taking general education materials to major veterinary schools. The company has learned that it can reach the market of established veterinarians by educating their younger colleagues.

Communication is a two-way process, and it's easy to forget about the receiving end. "The public" is a mixed bag of people, each of whom interprets the information generated by a biotechnology company based on a set of personal biases. No one, not even so-called public relations professionals, can fully predict how the public will react, as a group, to any piece of news. But it's safe to assume that the more informed people are about a subject, the more predictably and rationally they will respond.

People are inundated with information. They need clear reasons to listen to what companies have to say. It's important to make sure they're not listening just because they're afraid. A biotechnology company that makes it a regular habit to enlighten honestly about its technologies is likely to find a more moderated, even warm, reaction to its eventual products. A company can evoke positive interest by describing agricultural products with enhanced nutritional content, or diagnostic tests to speed the detection of common ailments. And, this opens a door to explaining the underlying technologies. Gradually, biotechnology loses the mystery that separates it from common experience. It becomes familiar, even comfortable. When products appear, they can be discussed, evaluated, and purchased.

Biotechnology companies must travel a long route from founders' visions to fruition of goals. They will find, as all frequent travelers know, that it pays to plan ahead.

Amanda Iles is an associate partner of the Talbott Group, 580 College Avenue, Palo Alto, CA 94306. These opinions are the author's own, and are not necessarily those of Bio/Technology. 